\title{
EL DERECHO DE CONFRONTACIÓN EN EL SISTEMA PROCESAL PENAL DE EL SALVADOR ${ }^{l}$
}

O DIREITO DE CONFRONTAÇÃO NO SISTEMA PROCESSUAL PENAL DE EL SALVADOR

THE RIGHT OF CONFRONTATION IN THE CRIMIINAL PROCEDURAL SYSTEM OF EL SALVADOR

\section{Rommell Ismael Sandoval Rosales ${ }^{2}$}

Licença CC BY:

Artigo distribuído sob os termos Creative Commons, permite uso e distribuição irrestrita em qualquer meio desde que $o$ autor credite a fonte original.

\begin{abstract}
Resumen: La reforma del proceso penal en EI Salvador modificó las reglas probatorias tradicionales heredadas del derecho continental inquisitivo español. Implicó introducir reglas adversativas para la práctica de la prueba testimonial y pericial en el juicio oral adversativo, como el interrogatorio directo y el contrainterrogatorio sugestivo para lograr la efectividad del derecho de confrontación. El artículo tiene por objetivo demostrar la diferencia de la técnica procesal entre un interrogatorio directo y un contrainterrogatorio. Se describen las principales causas o razones para la impugnación de testigos o peritos. A partir del método deductivo, también se describe de forma breve la naturaleza y objetivo de las objeciones en audiencia.
\end{abstract}

Palabras claves: cambio en el modelo procesal; interrogatorio directo; contrainterrogatorio; objeciones.

Resumo: A reforma do Processo Penal em El Salvador modificou as tradicionais regras probatórias herdadas do direito inquisitivo continental espanhol. Implicou introduzir regras adversativas para a prática da prova testemunhal e pericial no juízo oral adversativo, como o interrogatório e o contrainterrogatório sugestivo para alcançar a efetividade do direito de confrontação. $O$ artigo tem por objetivo demonstrar a diferença da técnica processual entre um interrogatório direto e um contrainterrogatório. Descrevem-se as principais causas ou razões para a impugnação de testemunhas ou peritos. A partir do método dedutivo, também são descritas, de forma breve, a natureza e o objetivo das objeções em audiência.

A Milagro, Fer, Noé, Ale y Javier.

Doctor en Derecho por la Universidad Autónoma de Barcelona. Fue miembro de las comisiones redactoras de los proyectos de Código Procesal Penal y Código Procesal Civil y Mercantil en EI Salvador. Ha sido consultor de programas de Reforma Judicial para USAID y otros cooperantes en EI Salvador, Guatemala, Nicaragua, Costa Rica, República Dominicana, Panamá, México y Honduras. Capacitador de derecho probatorio y litigación oral en los países mencionados. Es socio de la firma de abogados SBA y de I \& D Consulting. Profesor de derecho procesal en el doctorado en derecho de la Universidad Dr. José Matías Delgado. E-mail: rommellsand@yahoo.com 
Palavras chaves: mudança no modelo processual; interrogatório direto; contrainterrogatório; objeções.

Abstract: The Criminal Procedural reform in El Salvador changed the traditional rules of evidence inherited from the continental Spanish inquisitorial law. It involved introducing adverse rules for the practice of witnesses and expert evidence in the adverse oral judgement, such as interrogation and suggestive counter-interrogation to achieve the effectiveness of the right of confrontation. The article aims to demonstrate the difference in procedural technique between direct interrogation and counter-interrogation. It describes the main causes or reasons for challenging the witnesses or experts. Using the deductive method, it also briefly describes the nature and objective of the objections in a court hearing.

Keywords: change in the procedural-interrogatory model law-counterinterrogation-objectives.

\section{INTRODUCCIÓN}

El Salvador en los años noventa impulsó la reforma del sistema judicial por medio de una serie de proyectos legislativos. Con la asistencia técnica del Proyecto de Reforma Judicial II, de USAID, se redactó el proyecto de Código Procesal Penal (en adelante CPP), fundamentado en las orientaciones del Código Procesal Penal Tipo para Iberoamérica, el cual fue sometido con iniciativa de ley a la Asamblea Legislativa en el año 1994. El CPP fue aprobado finalmente en 1996, aunque entró en vigor en el año 19983.

Durante el período de vacatio legis (entre 1997 y 1998), se redactaron reformas al CPP, inspiradas en las Reglas de Evidencia de Puerto Rico para la práctica de la prueba testimonial y pericial, por medio de un interrogatorio directo, contrainterrogatorio sugestivo, interrogatorio redirecto y recontrainterrogatorio sugestivo. La misma técnica se aplicaría para la prueba pericial.

Al entrar en vigencia en 1998, las reglas adversativas ya estaban comprendidas y se comienzan a poner en práctica por los litigantes. El CPP de 1998, fue sustituido posteriormente por el vigente en el año 2012, bajo un modelo de tendencia acusatoria en su etapa preliminar y adversativa en el juicio oral.

El juicio oral o la vista pública, de acuerdo con legislación procesal penal, es la etapa principal del proceso en el procedimiento común en el que es indispensable la presencia de todos los sujetos procesales (tribunal, fiscal, defensor, imputado, víctima y querellante si los hubiere) para que pueda celebrarse. Según el art. 193 de la Constitución de la República, le incumbe al Fiscal General de la República, la dirección funcional de la Policía en la investigación de un hecho punible, la orientación

3 El CPP salvadoreño, en el año de 1996, incluyó en el art. 348 las primeras reglas adversativas para la práctica de la prueba testimonial y pericial, por medio de interrogatorio y contrainterrogatorio, basado en las Reglas de Evidencia de Puerto Rico de 1979. FONTANET expresa que en América Latina hay un alejamiento de la figura del juez de lo penal "inquisidor" ("juez de instrucción), se han incorporado reglas del sistema adversativo angloamericano, FONTANET, Julio. Principios y Técnicas de la Práctica Forense. $2^{\text {a }}$. Ed., San Juan Puerto Rico: Jurídica Editores, 2002. 
de la recolección de las evidencias y su custodia. En otras palabras, la Fiscalía General es responsable de desplegar sus actividades investigativas y de dirección de la investigación durante las diligencias iniciales y durante la etapa de preparación formal del proceso penal.

A partir de ese cambio de paradigma procesal, el legislador separó la función investigadora de la decisora, atribuyendo estas facultades a órganos distintos. La Fiscalía dirige la investigación o investiga directamente, prepara la promoción de la acción penal fundada en evidencia de cargo y promueve el dictamen de acusación4.

\section{1.- LAS FUENTES Y LOS MEDIOS DE PRUEBA EN EL CÓDIGO PROCESAL PENAL}

A la Fiscalía o a los acusadores le corresponde la carga de investigar, y la carga procesal de "probar" los hechos en el juicio oral para intentar desvanecer la garantía de inocencia del acusado, entonces, la parte acusadora debe convencer al Juez o tribunal sobre la certeza de que el hecho ha existido tal y como se ha introducido por los medios probatorios pertinentes en la audiencia5; y que el imputado es responsable del hecho punible.

La carga de la prueba bajo la responsabilidad del fiscal se convierte en una garantía del imputado que preserva su estado de inocencia. Por lo que esta regla no solo se establece para las partes procesales sino también para evitar que el órgano judicial se convierta en investigador o instructor6.

La Fiscalía General de la República para racionalizar la investigación y persecución de los delitos, ha emitido una Política de Persecución Penal7. Esta es una política general, para enfocar una adecuada investigación y eficiente ejercicio de la acción penal con el objeto de reducir la impunidad. La política se fundamenta en los principios de respeto a la dignidad humana, legalidad, objetividad, racionalidad, proporcionalidad, igualdad, eficiencia y eficacia, unidad de acción y dependencia jerárquica. La FGR, asimismo, ha emitido, una Política de Persecución Penal en materia de Violencia contra las Mujeres8, vinculada a la política de persecución general, la cual se justificó ante la alta tasa de muertes violenta de mujeres, tipificada como feminicidio.

$4 \quad$ GIMENO SENDRA sitúa los principios de inmediación y concentración, como integrantes de los principios del procedimiento, que se refieren a la relación entre el órgano jurisdiccional y el material fáctico introducido por las partes en el juicio. En las audiencias inicial y preliminar en el proceso penal, las partes tienen la carga procesal de practicar, mediante interrogatorios a testigos o a la víctima, la prueba con la que desean llevar al Juez de paz o instrucción, en su caso, para que tome una determinada decisión. Si los jueces toman decisiones sin que se produzcan interrogatorios, asumen su responsabilidad. GIMENO SENDRA, José Vicente. Fundamentos del Derecho Procesal, jurisdicción, acción y proceso. Editorial Civitas S.A., 1981., pp. 228 a 232. GIMENO SENDRA, José Vicente; Derecho Procesal. Proceso Penal. Valencia: Tirant lo Blanch, 1993. p. 83. debería exigir en un modelo acusatorio adversativo que en toda audiencia se debería practicar prueba.

Fiscalía General de la República, Política de Persecución Penal, El Salvador, 2017.

Fiscalía General de la República, Política de Persecución Penal en materia de violencia contra las mujeres, El Salvador, 2017. 


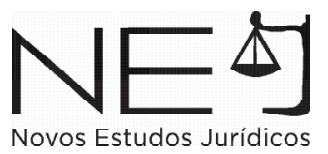

El legislador establece en el CPP una libertad de fuentes de prueba, siempre que se respete su legal obtención, así manifiesta en el art. 176 del CPP que "los hechos y circunstancias relacionados con el delito podrán ser probados por cualquier medio de prueba establecido en este Código y en su defecto, de la manera que esté prevista la incorporación de pruebas similares, siempre que se respeten las garantías fundamentales de las personas consagradas en la Constitución y demás leyes".

El límite a la libertad probatoria es el respeto al principio de legalidad y a la regla de la pertinencia. Este último se entiende que todo elemento probatorio debe tener relación directa para demostrar la existencia del hecho y la responsabilidad de los imputados. Pero el CPP amplía la regla de pertinencia al autorizar prueba para la impugnación de la credibilidad de la fuente de prueba. Es decir, que el fiscal o el defensor, según sea el caso, podrá atacar la evidencia de la parte contraria, a través de los contrainterrogatorios, atacando la credibilidad de los testigos y peritos de cargo, o de sus declaraciones.

Dice el art. 177 del CPP, respecto a la regla de la pertinencia y utilidad de la prueba "será admisible la prueba que resulte útil para la averiguación de la verdad y pertinente por referirse directa o indirectamente a los hechos y circunstancias objeto del juicio, a la identidad y responsabilidad penal del imputado o a la credibilidad de los testigos o peritos... La prueba impertinente es inadmisible. Se podrá excluir la prueba pertinente, previa consulta con las partes, cuando lo exija un interés preponderante o implique dilación de procedimientos o presentación de prueba acumulativa. El testimonio de referencia, de carácter o conducta y de hábito, sólo será admisible en los casos previstos en este Código".

El art. 177 admite, que los sujetos procesales puedan rechazar prueba por impertinente o excluir prueba, no solo por su ilegalidad, sino porque resulta acumulativo y puede dilatar exageradamente el procedimiento, como en el caso de múltiples testigos. Serán las partes las que seleccionen la prueba que necesitarán. También las reglas han permitido la admisión excepcional de prueba de referencia bajo determinadas condiciones, así como la de carácter, conducta y hábito.

El Título V "de la prueba" del CPP se subdivide en los capítulos de las disposiciones generales (capítulo I); actos urgentes de comprobación (capítulo II) que consisten en inspección en el lugar de los hechos (sección primera); disposiciones sobre el reconocimiento de cadáver y exhumación (sección segunda); allanamiento y registro con orden y sin orden judicial, requisa personal, inspección, registro de vehículos, muebles y compartimientos cerrados, inspecciones corporales e intervenciones corporales (sección tercera); el CPP desarrolla reglas sobre la prueba electrónica (sección cuarta). 
En el capítulo III se despliegan las disposiciones sobre la prueba testimonial y la prueba testimonial de referencia (sección primera); prueba de carácter y prueba de hábito (sección segunda), por medio de la cual se adoptan la prueba de modus operandi, muy útil para patrones de actividades delincuenciales o para el juzgamiento de agrupaciones ilícitas; en el capítulo IV se legisla sobre la prueba pericial (peritos); en el capítulo $\mathrm{V}$ incluye las reglas novedosas de prueba mediante objetos; en el capítulo VI desarrolla la prueba documental; en el capítulo VII dispone sobre las reglas de la cadena de custodia; los procedimientos para los reconocimientos de una persona, pluralidad de reconocimiento y reconocimiento por fotografías; en el capítulo IX dispone sobre la confesión del imputado, tanto judicial como extrajudicial.

Por su lado, una ley especial regula las intervenciones telefónicas o las comunicaciones que realice la unidad especializada de la Fiscalía a los sospechosos de ser responsables de la realización de un delito, todo bajo autorización judicial y con reglas que eviten el abuso de dicho recurso.

Las reglas sobre la prueba están vinculadas con las disposiciones del CPP referente a la investigación del hecho delictivo. Las etapas de instrucción, de ofrecimiento, admisión de prueba y de la práctica de ésta, se realiza por medio de los interrogatorios y contrainterrogatorios.

\section{2- LA PRUEBA TESTIMONIAL}

Como expresan los arts. 202 a 219 del CPP, toda persona tiene aptitud para ser testigo, si declara sobre los hechos con conocimiento propio y directo9. Bajo esta disposición sólo son admisibles, por regla general, las declaraciones de los hechos que se hayan obtenido de forma directa por las capacidades sensoriales del testigo. Es inadmisible, por lo tanto, la prueba de testigo cuyo conocimiento haya sido obtenida por el "rumor" o de "oídas" pero sin haberlas presenciado.

Ahora bien, el art. 221 del CPP admite de manera excepcional, la prueba de referencia en el entendido que son declaraciones de testigos que no han presenciado los hechos (art. 220 del CPP). Así se enumera que se admite la prueba de referencia en los casos de muerte, enfermedad grave u otra circunstancia que haga imposible o difícil que comparezca el testigo; en los casos en los cuales los testigos son policías encubiertos; cuando exista una retractación de la víctima o el testigo, para controlar la credibilidad de estos; y en los casos de declaraciones o manifestaciones expresadas por el testigo, la víctima o el imputado de manera consciente y espontánea, en circunstancias que

$9 \quad$ En el derecho probatorio moderno se reconoce que todas las personas son aptas para ser testigos. El CPP del 2010 reconoce la posibilidad que cualquier persona que tenga conocimiento propio y directo sea llamado a una entrevista y luego a declarar en juicio. IMWINKELRIED, Edward J. Evidentiary Foundations, 5 Ed., USA: LexisNexis, 2002. p. 24. Coincide con este autor, CHIESA APONTE, Ernesto L. Derecho Procesal Penal de Puerto Rico y Estados Unidos. San Juan: Editorial Forum, 1995. p. 321. 


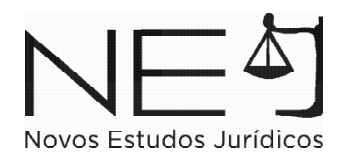

implicaban un perjuicio a los intereses de quien lo realizó o de un tercero.

La calidad de testigo se adquiere con la identificación por las partes o por el juez, durante la etapa investigación o preparación del caso $^{10}$. El testimonio como medio de prueba tiene por objeto acreditar los hechos, o sea, demostrar la existencia o inexistencia de hechos alegados por las partes en sus escritos o aquellos otros que puedan tener una relación directa con ellos, así como los que se aporten al proceso como alegaciones complementarias y aclaratorias. Se trata, en cualquier caso, de hechos que han ocurrido con anterioridad al acto del juicio o de la vista. Lo que el testigo realmente hace en el juicio es expresar una versión de los hechos conocidos a través de su capacidad de percepción, memoria y expresión narrativa.

El CPP dice que toda persona tiene capacidad para ser testigo: "Capacidad de testigo Art. 202- Toda persona es apta para ser testigo, salvo disposición legal en contrario" y "Obligación de testificar Art. 203.- Toda persona tendrá la obligación de concurrir al llamamiento judicial y declarar la verdad de cuanto sepa y le sea preguntado sobre los hechos que se investigan, salvo las excepciones establecidas por la ley."

Establece el art. 209 del CPP vigente, que antes de comenzar la declaración, los testigos serán instruidos acerca de sus obligaciones y responsabilidades, como de las penas de falso testimonio, para cuyo efecto el Juez de lo penal les instruirá sobre los artículos pertinentes del Código Penal. Inmediatamente después los testigos prestarán declaración ante el Juez de lo penal y las partes, juramento o promesa, de decir la verdad.

Los interrogatorios en audiencia podrán sufrir algunas modulaciones en cuanto a si el testigo es un niño(a), si la víctima es mujer en determinados delitos, o si se trata de un testigo o víctimas sujeta al régimen especial de protección. Es decir, en estos últimos casos se incorporan reglas para la protección de la integridad moral y psíquica de la persona.

La dinámica del examen de testigos estará bajo la moderación del juez de lo penal, pero a petición de parte. Es decir que el juez de lo penal moderará la actividad de la práctica de interrogatorios y las partes pueden controlarse mutuamente o al mismo tribunal por medio de las "objeciones o reparos" fundadas, oportunas y específicas. Todo ello bajo el espíritu de un sistema adversativo.

\section{3.- LA PRUEBA DE PERITOS}

Los peritos son personas que por su conocimiento técnico, científico, artístico y práctico realizan

$\overline{10}$ MORENO CATENA, Víctor, El Secreto en la Prueba de Testigos del Proceso Penal. Madrid: Editorial Motecorvo S.A, 1980. p. $26-27$. 
procesos de indagación sobre los hechos y generan explicaciones lógicas. En algunos casos son hipótesis razonables en otras conclusiones, dependiendo de la evidencia con la que puedan contar. Los peritos pueden ser de carácter permanente, si pertenecen a una organización estatal que puede dedicarse o no en sus funciones habituales a la investigación criminalística. En otros casos pueden ser accidentales, si se les nombra para una experticia forense en particular.

En cuanto a la prueba pericial, basta con señalar que normalmente quién asume el carácter de perito es un tercero ajeno al proceso que es experto en una técnica, ciencia o arte y que es instruido, sea por la parte (perito de parte) o por el juez de lo penal (perito judicial) para que realice una determinada investigación técnica, científica o artística sobre determinados hechos en controversia para que explique conforme a su saber qué fue lo que pasó, cómo sucedió, quién pudo ser el responsable, cuál es el nexo causal y cuáles son los resultados o consecuencias.

Ahora bien, un perito en principio no ha presenciado los hechos constitutivos del delito, llega después a la escena del delito o es invitado posteriormente a que realice las investigaciones y análisis técnicos que sean necesarios. En algunos casos es llevado a declarar a audiencia judicial mediante interrogatorio y contrainterrogatorio, pero si no existe controversia sobre su informe pericial, éste puede ser "estipulado" art. 178 del CPP, sin necesidad de que declare en audiencia.

El procedimiento del vigente CPP, para el nombramiento de peritos, fue confusamente elaborado por el legislador. En el proyecto original del CPP se instituyó que los peritos normalmente serían nombrados por las partes, especialmente por la Fiscalía durante sus actos iniciales de investigación o durante la investigación formal (ahora denominada instrucción formal), porque la carga de la prueba es dicho sujeto procesal. Sin perjuicio que los querellantes y defensores pudieran nombrar los propios. En el proyecto, los peritos permanentes con los que cuenta el Estado para su investigación son justamente los mencionados en el art. 226 del CPP.

\section{4.- LA PRÁCTICA DE LOS INTERROGATORIOS}

La vista pública se realizará con la presencia ininterrumpida del tribunal y de las partes, art. 367 del CPP, y será pública (art. 369 del CPP). Es así como el día y la hora que se hubiera fijado previamente el tribunal se constituirán en la sala de audiencias. Se resolverán previamente cuestiones incidentales y se autorizará a las partes para que presenten su teoría del caso por medio de su alegación inicial, empezando por el fiscal y querellante para que expongan la acusación y luego la defensa. Bajo el CPP, las partes pueden ordenar su prueba según su estrategia y teoría del caso, es así que luego de la declaración o abstención de la declaración del imputado, el primer turno será de los acusadores, y al finalizar el mismo se recibirá la prueba de la defensa. 


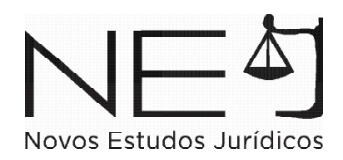

La base procedimental de la práctica de la prueba en audiencia en juicio oral y público (art. 369 y 371 del CPP) es por medio del interrogatorio directo y contrainterrogatorio de testigos o peritos, en el que se admiten preguntas sugestivas (así como examen redirecto y recontrainterrogatorio). Es decir, bajo la técnica de litigación adversativa en que deberán llevarse a cabo la producción probatoria en la vista pública, bajo los principios propios del proceso penal (arts. 387, 388 y 389 del CPP). E incluso, durante las audiencias inicial, preliminar y cualquiera en la que deba de producirse prueba.

El procedimiento para desarrollar la técnica de interrogatorio es el siguiente:

Interrogatorio directo: Estas preguntas las hará la parte que ofreció al medio probatorio (víctima, testigo o perito). Su finalidad es probar una afirmación fáctica;

Contrainterrogatorio: Luego de finalizado el interrogatorio, la parte adversa, en el ejercicio del derecho de defensa (confrontación) realizará el contrainterrogatorio a la víctima, testigo o perito. La principal finalidad es impugnar la legalidad, la credibilidad o la pertinencia de la prueba;

Interrogatorio redirecto: Lo realizará el abogado que hizo el primer interrogatorio. Tiene la finalidad de "rehabilitar" la prueba (víctima, testigo o perito) luego que sufrió la confrontación del contrainterrogatorio; y,

Recontrainterrogatorio: Este es la última oportunidad procesal, y lo hará el abogado que practicó el contrainterrogatorio. Su finalidad es continuar impugnando la credibilidad de la prueba de la parte que la ofreció.

En cada una de las oportunidades procesales, las partes pueden ofrecer e introducir prueba material por medio de interrogatorios, como documentos u objetos y autenticarlas por el procedimiento correspondiente, ver arts. 212, 242 y siguientes del CPP. También vale recalcar que únicamente las partes, no el juez o presidente del tribunal, pueden efectuar las objeciones técnicas que sean necesarias (arts. 210-211 del CPP y arts. 407 a 410 del CPCM).

\section{5.- INTERROGATORIO DIRECTO}

El interrogatorio directo es el primer interrogatorio que uno de los abogados efectúa a un testigo"11, art. 209 inciso $4^{\circ}$ del CPP dice "el juez le concederá la palabra a la parte que presenta al testigo, para que formule el interrogatorio directo". El interrogatorio directo es la oportunidad procesal del abogado o fiscal que llama a los testigos (o peritos) que está en su turno de presentación de prueba. En el interrogatorio directo "la parte que presenta al testigo intenta convencer y persuadir

11 STRONG, John W. McCormick on Evidence. $5^{\text {th }}$ Ed. Minn: Hornbook Series West Group, 1999. pp. 10-18. Se basa en preguntas abiertas. Normalmente no se utiliza el interrogatorio sugestivo, pero de manera liberal se puede autorizar en los casos de acreditación del testigo o perito. 
al juzgador de la veracidad de sus alegaciones...en el interrogatorio directo el protagonista es el testigo y no el interrogador"12.

Por su parte, bajo la misma línea del modelo adversativo, el art. 366 del Código Procesal Civil y Mercantil (CPCM), el cual actúa como derecho procesal común, dice: "Interrogatorio directo Art. 366.- Las preguntas se formularán oralmente, con la claridad y precisión debidas, y las hará en primer lugar la parte que propuso la prueba. Los testigos responderán en forma oral, directa, y concreta a las preguntas que se les formulen, y sobre aquello de lo que tenga conocimiento personal. No podrán utilizar borradores ni notas, aunque pueden consultar apuntes o documentos cuando la naturaleza de la pregunta lo exigiera y hubiese autorización del juez. La parte contraria tendrá acceso a dichos apuntes o documentos. En sus declaraciones los testigos no podrán emitir opiniones ni hacer especulaciones".

Lo que normalmente se recomienda es que el primer interrogatorio directo, comience realizando preguntas de acreditación de testigos, aunque en el CPP el juez que preside la audiencia ya lo hizo, al contrario, en el CPCM quien lo hace es el abogado que interroga, art. 364 del CPCM Identificación y acreditación del testigo. El juez, previamente al acto de la declaración, tomará al testigo juramento o promesa de decir verdad. De inmediato, le cederá la palabra a la parte que lo hubiera ofrecido como medio de prueba, la cual, mediante interrogatorio acreditará a su testigo e identificará preguntándole su nombre, edad, estado familiar, domicilio y ocupación. A continuación, se procederá al examen."

Entonces, en el proceso penal, el orden por medio del cual puede comenzar el primer abogado que interroga a su propio testigo tiene que orientar al tribunal quién es la persona que está allí, por qué razón se encuentra, cómo conoce los hechos y si tiene capacidad de recordar y describirlos. En la práctica del Tribunal, en algunas ocasiones el juez es el que interroga al testigo y perito sobre su identificación, en otros se deja que sea el abogado que lo haga.

Se sugiere llevar este orden, sin perjuicio que la práctica y la estrategia, indique otra cosa:

Preguntas de acreditación del testigo o del perito, si el Juez o presidente del tribunal no lo hizo, o si el Tribunal prefiere que los abogados realicen el interrogatorio desde la acreditación del cual dependerá de la práctica;

Preguntas introductorias sobre los hechos en el caso del testigo, y sobre la actividad sujeta a la pericia; 


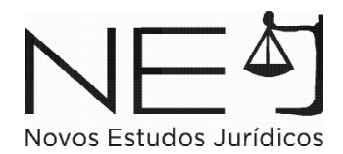

Preguntas descriptivas sobre los hechos, circunstancias y el responsable en el caso del testigo. Pero en el caso del perito hay que preguntar sobre los contenidos y alcances del estudio realizado. Hay que recordar que el perito conoce los hechos después a petición de uno de los sujetos procesales, tiene tiempo para reconstruir y explicar los hechos desde la ciencia o técnica, en cambio, el testigo explicará los hechos porque los presenció, y lo hará de forma natural.

Para el interrogatorio directo, se recomienda que las preguntas faciliten un relato sobre los hechos, tiene que ser ordenado (en lo posible de modo cronológico), descriptivo, sencillo e interesante. Las preguntas deben ser sencillas y comprensibles. De igual manera las respuestas. Por lo que no debe presumir que el juez de lo penal entiende lo que está diciendo el testigo.

Se recomiendan preguntas abiertas, para evitar ser objetado, tales como: ¿Quién? (las preguntas deben permitir identificar ante el juez quién es el testigo y la persona contra quién se declara); ¿Qué? (¿qué fue lo que sucedió?), esta pregunta es esencial para verificar si el hecho es una conducta típica, si es una acción u omisión; ¿Cómo?

Estas preguntas deben permitir que el testigo describa cómo sucedieron los hechos, y establecer el grado de participación de la persona imputada; ¿Dónde? (lugar de los hechos, descripción general, municipio, si fue en la calle o en un lugar cerrado como un hogar o fábrica; ¿Cuándo? (¿fecha y hora de los hechos?); ¿Por qué? (explicar la relación del testigo con las personas o con los hechos o porque se encontraba allí); luego se utilizan otro tipo de oraciones para que el testigo siga declarado como "explique, diga, describa testigo...", o similares.

Es necesario recordar que el interrogador en directo no puede hacer preguntas sugestivas. Una pregunta sugestiva contiene un hecho afirmado por el interrogador: Así normalmente se pregunta: "La realidad testigo...", "es cierto testigo...", o "testigo usted afirmó anteriormente qué..." Estas preguntas las prohíbe el art. 209 del CPP en el interrogatorio directo, cuando dice: "El juez que preside, moderará el examen del testigo y evitará que conteste a preguntas capciosas e impertinentes, procurando que el interrogador no ejerza presiones indebidas ni ofenda la dignidad del declarante. En el interrogatorio directo, por regla general, estarán prohibidas además las preguntas sugestivas; sin embargo, quien preside podrá permitir la sugestividad en el interrogatorio directo, cuando el testigo sea hostil, cuando se interrogue a la parte contraria, al testigo identificado con ésta, a una persona que, en virtud de su mayor edad, limitada educación o causa semejante, tenga dificultad de expresión, o que por razones de pudor esté reacio a deponer libremente."

Pero, el mismo artículo a continuación, dice que será permitida la sugestividad en el interrogatorio directo, cuando el testigo se identifique con aquella, se vuelva hostil, cuando se interrogue a una 
persona que, por su mayor edad, limitada instrucción o causa similar, se le dificulte expresarse o que por razones de pudor esté renuente a declarar libremente. En todo caso se deberá respetar la dignidad del testigo.

Es decir, que excepcionalmente los jueces podrían autorizar a un abogado a hacer preguntas sugestivas en el interrogatorio directo, la "excepción para que se permita preguntas sugestivas durante el interrogatorio directo está basada en que, si no se permitieran, sería muy difícil obtener información valiosa para la resolución de la controversia" ${ }^{13}$, como en los casos en los testigos de la propia parte se comportan de manera hostil, es de escasa cultura o no puede expresarse adecuadamente.

En cuanto a los testigos, si son de la Fiscalía, se debe permitir que corroboren al responsable y que demuestren que los hechos encajan en los elementos objetivos del tipo penal y de la conducta del investigado. Por supuesto que esto debe ajustarse a la realidad. No se trata de falsear o cometer un fraude.

En el caso de los peritos se recomienda que:

Se acredite la capacidad técnica del perito.

Se acredite que el procedimiento técnico o científico criminalístico es el idóneo y aceptado para explicar los hechos, pero debe ser ajustado a los puntos de pericia solicitados, por lo que el dictamen tiene que ser ordenado (en lo posible de modo cronológico), descriptivo, sencillo e interesante.

Las preguntas deben ser sencillas y comprensibles. De igual manera las respuestas. Por lo que no debe presumir que el juez de lo penal entiende lo que está diciendo el perito. El perito debe concluir. No puede haber pericias sin conclusión de los puntos requeridos.

El informe pericial puede orientarse a explicar los hechos por medio de una teoría, con base a las pruebas científicas realizadas. Es decir, debe tener una base real.

Hay que introducir el dictamen pericial mediante preguntas para acreditarlo ante el juez, debiendo sentar primero las bases de pertinencia y que dicho instrumento es conocido o fue elaborado por el perito.

El sistema adversativo permite introducir en audiencia por medio de interrogatorios prueba material. El Código salvadoreño incluyó reglas para la introducción de prueba material que precisa una exigencia rigurosa como es la cadena de custodia, como otra menos rigurosa.

13 EMmANUELLI JIMÉNEZ; Prontuario de Derecho Probatorio Puertorriqueño, Reimpreso en Reprográfica, San Juan Puerto Rico, febrero 1999 , p. 296. Las reglas de evidencia de Puerto Rico hacen una excepción al uso de preguntas sugestivas. Normalmente la parte le solicita autorización al juez para tratarlo como "hostil". Es decir, a su propia prueba lo interroga con preguntas cerradas. 
Dice el art. 212 del CPP “Facultades de las partes en el interrogatorio Art. 212.- El juez podrá autorizar al testigo que consulte documentos, notas escritas o publicaciones, cuando por la naturaleza de la pregunta fuere necesario, sin que por este solo hecho, tales documentos puedan incorporarse como prueba a la vista pública.

Si el testigo consultare un documento para responder a las preguntas realizadas durante el interrogatorio directo o el contrainterrogatorio, la parte contraria podrá examinarlo y presentar la totalidad del texto de dicho documento." Entonces, bajo el sistema del CPP vigente se admite la presentación de documentos o prueba material, siempre y cuando previamente y mediante la práctica del interrogatorio, las partes pongan al juez en disposición de admitirlo, mediante la figura como "sentar las bases evidenciarias". Este procedimiento no es más que el testigo le explique al juez por medio del interrogatorio de su parte, la razón del conocimiento de dicho medio, las razones de su existencia o si el declarante lo elaboró o si conoce quién lo elaboró. Las preguntas del interrogador deben sentar las bases y demostrar la capacidad de reconocimiento sobre esas fuentes materiales son idénticas (arts. 209 y 212 del CPP y 242-243 del CPP).

\section{6.- EL DERECHO DE LA CONFRONTACIÓN Y EL CONTRAINTERROGATORIO}

La práctica de confrontación e impugnación de testigos, de acuerdo con el art. 209 del CPP son utilizadas por los abogados y fiscales en los tribunales salvadoreños, como una innovación frente a los demás modelos continentales de juicio oral desde el año $1998^{14}$.

El principio de confrontación, como derivación del derecho constitucional de defensa, exige que el acusado pueda "carearse" con los testigos de parte contraria. Pero el careo no significa la realización del inquisitivo acto de investigación en la que se pone a un testigo frente a otro para que el juez intermedie quién dice la verdad. Esa es una práctica inconstitucional, porque no es la función del juez de instrucción, para eso están las audiencias. Será el juez el que le dé credibilidad a las manifestaciones. El derecho al careo implica que el imputado pueda estar presente en la audiencia en donde los testigos de la parte acusadora o la víctima estén deponiendo y pueda confrontarlas, si así lo desea, por medio de un contrainterrogatorio a través de su defensor. El contrainterrogatorio es la verdadera efectivización del derecho de defensa en una audiencia. Asimismo, le asiste el derecho al acusado de confrontar a sus propios testigos, cuando el testimonio de éstos le resulta adverso en la audiencia ${ }^{15}$.

14 CHIESA, Ernesto L. Tratado de Derecho Probatorio, Reglas de Evidencia de Puerto Rico y Federales. República Dominicana: Editora Corripio, 1998. p. 365.

15 CHIESA APONTE, Ernesto L. Derecho Procesal Penal de Puerto Rico y Estados Unidos. San Juan: Editorial Forum, 1995. p. 389-390. De allí que los contenidos de la Ley de Protección de Testigos y Víctimas, no sea constitucionalmente. La parte que contrainterroga, lo que pretende con esta impugnación, es restar credibilidad ante el Juez de lo penal sobre un testigo o sobre la confiabilidad del conocimiento de los hechos de éste. 
En el ejercicio del derecho de defensa el acusado puede contrainterrogar a los testigos de cargo, ello basado en los Art. 8.2 f) de la Convención Americana de Derechos Humanos, y el 14.3 e) del Pacto Internacional de los Derechos Civiles y Políticos, que determinan el derecho del imputado a interrogar testigos. En el proceso penal, tal reconocimiento constituye la diligencia más importante para definir la situación jurídica del imputado, con mayor razón resulta un imperativo permitir la confrontación a la prueba de cargo en la audiencia inicial y preliminar. De allí que sea necesario exigir la práctica de interrogatorios a la víctima y testigo de cargo por parte de la Fiscalía, para luego someterlo a un contrainterrogatorio. Con ello se cumpliría un mínimo de actividad probatoria ${ }^{16}$. Bajo el principio de igualdad procesal, la fiscalía, tiene la oportunidad procesal de contrainterrogar la prueba presentada por la defensa.

En el sistema judicial americano, los abogados tratan de impugnar (restarle credibilidad) a los testigos durante el contrainterrogatorio o "cross examination"17. Se realizan preguntas sugestivas o cerradas para refutar la declaración testifical, es decir, para desacreditar el testimonio. La parte que contrainterroga, lo que pretende es restar fe ante el Juez o jurado sobre un testigo o sobre la confiabilidad del conocimiento de los hechos de éste.

De acuerdo con CHIESA APONTE, "la credibilidad de un testigo puede ser impugnada por cualquier parte, incluyendo a la parte que llama al testigo. El testigo está obligado a contestar cualquier pregunta pertinente a su credibilidad, aunque en cuanto se le pregunte sobre materia que solo se relaciona con su credibilidad y no con los hechos sobre los que ha declarado, puede invocar el derecho contra la autoincriminación"18. En ese sentido, bajo las regulaciones del juicio oral adversativo toda prueba que pretenda impugnar o sostener la credibilidad de un testigo, en cuanto a su veracidad o mendacidad, es pertinente y admisible.

Entonces, el testigo que esté sentando en la silla de deposición en la audiencia, debe contestar (está obligado a hacerlo ante el juez) no solo preguntas sobre los hechos relacionados directamente a la controversia o hecho investigado, sino sobre lo que afecte su credibilidad: relaciones con el imputado o el caso, parentesco o interés; si efectivamente ha presenciado los hechos y que no es prueba de referencia; las condiciones del entorno cuando estuvo presente ante los hechos; la capacidad sensorial; capacidad de memoria u otros.

16 SANDOVAL ROSALES, Rommell Ismael y AAVV. Código Procesal Penal comentado: volumen 1. San Salvador: Consejo Nacional de la Judicatura, 2018

IMWINKELRIED, Edward J. Evidentiary Foundations, 5 Ed., USA: LexisNexis, 2002. p. 185

18 CHIESA APONTE, Ernesto L. Derecho Procesal Penal de Puerto Rico y Estados Unidos. San Juan: Editorial Forum, 1995. p. 324. Para este autor, con la evidencia de impugnación lo que una parte pretende es arrojar "sombras" sobre la credibilidad de un testigo o sobre la confiabilidad de un testimonio. 


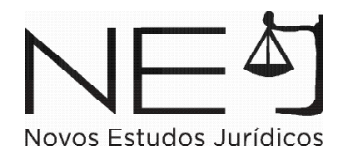

Las declaraciones testificales determinan el resultado del juicio, lo cual es cierto al menos en cuanto a la credibilidad de éstos. Para que el juez crea en la información proporcionada por el testigo, en primer lugar, debe lograrse que sea creíble y que lo manifestado por éste sea verdad ${ }^{19}$. Ello implica que el derecho a contrainterrogar permite al juez un mejor panorama sobre los hechos.

La impugnación o refutación de testigos son las actuaciones procesales probatorias y pertinentes para impugnar un testigo que un abogado (sea defensor o fiscal) de la parte adversa realiza durante una audiencia, introduciendo evidencia o prueba durante el contrainterrogatorio para arremeter contra la credibilidad de un testigo o de su deposición ${ }^{20}$. Su objeto estratégico es disminuir el valor probatorio o la credibilidad del testimonio vertido en el interrogatorio directo, al testigo o a ambos ante los ojos del tribunal.

Es así como los propósitos del contrainterrogatorio son:

Intentar desacreditar el testimonio del testigo o perito la parte contraria;

Descubrir inconsistencias de la declaración testifical contraria;

Atacar la credibilidad del testigo, o perito con base en sus propias declaraciones previas efectuadas en audiencia o fuera de ella, igual se puede impugnar por su comportamiento o porque aparezca como testigo criteriado o por cualquier otra razón que indique interés en declarar en juicio; e,

\section{IDENTIFICAR UNA DECLARACIÓN QUE LE FAVOREZCA.}

A diferencia del interrogatorio directo, en el contrainterrogatorio no se hacen preguntas cronológicas, sino por "temas o áreas" que muestren la vulnerabilidad del testigo o perito, por lo tanto, deberán ser específicas y definidas a atacar el testimonio o la credibilidad del testigo.

En un proceso adversativo que admite preguntas sugestivas el litigante no debe repetir al director, haciendo preguntas como las siguientes: ¿Quién es? ¿A qué se dedica? ¿Por qué estaba en el lugar de los hechos? Porque las respuestas fortalecerán la teoría del caso del abogado de la parte contraria.

En el turno del contrainterrogatorio, se recomienda hacer preguntas que sean cerradas o sugestivas para mantener el control de quién declara en audiencia. Esto es, formuladas como

\footnotetext{
19 GOLDBERG, Steven H. Mi primer Juicio Oral. Buenos Aires: Heliasta, 1994. p. 86 y ss. Para este autor, la habilidad del abogado puede influir de manera relevante para que el órgano juzgador adquiera conciencia en la credibilidad de su testigo y en el descrédito de la parte contraria.

20 QUIÑONES VARGAS, Héctor. Las Técnicas de Litigación Oral en el Proceso Penal Salvadoreño. EI Salvador: PAS/DPK Consulting, 2003. p. 235.
} 
aseveraciones o afirmaciones que el deponente tendrá que responder "sí" o "no", o en forma negativa o positiva, sin permitir que explique o ahonde su respuesta: Por lo que el abogado que contrainterroga debe mantener bajo control las respuestas del testigo para poder identificar contradicciones.

El objetivo del contrainterrogatorio sugestivo es restar credibilidad a la fuente de prueba. Se trata de poner en duda la capacidad de la fuente de prueba testifical para recordar los hechos correctamente o con detalles, se trata de impugnar directamente por su compromiso con una de las partes y no con la verdad, se intenta restar valor probatorio por su falta de capacidad narrativa.

En lo que concierne a los peritos, el objetivo es intentar restarle credibilidad al propio experto, sea porque carece de los estudios, preparación o especialidad técnica o científica en las ciencias criminalísticas, porque se descubra que ha cometido un error en la identificación o tratamiento de la evidencia, o porque utilizó un procedimiento erróneo o que pudo haber contaminado la escena del delito o el resultado de la pericia.

El contrainterrogatorio lo lleva a cabo el abogado de la parte contraria al testigo o perito ofrecido por la parte que realiza el interrogatorio directo ${ }^{21}$. Como se trata de un testigo que es presentado como prueba por la parte contraria, el abogado que contrainterroga puede hacer preguntas sugestivas porque el propósito del contrainterrogatorio es buscar la verdad o impugnar la credibilidad del testigo 22 .

Ahora bien, a partir de la entrada en vigor del CPCM, bajo la regla del art. 367 del CPCM, la técnica de contrainterrogatorio complementa, las reglas del proceso penal. Así dice el art. 367:

\section{"CONTRAINTERROGATORIO}

Art. 367.- Finalizado el interrogatorio directo, si la parte contraria manifiesta su deseo de contrainterrogar al testigo, el juez o el presidente del tribunal le concederá la palabra al efecto, permitiendo las preguntas sugestivas."

Durante el contrainterrogatorio, la parte que lo haga podrá utilizar, documentos, actas de declaraciones anteriores del testigo o deposiciones que hubiera rendido y que versen sobre los hechos en cuestión, para el efecto de demostrar o desvirtuar contradicciones, o para solicitar las aclaraciones pertinentes. La parte que sometió al testigo al interrogatorio directo podrá interrogarlo de nuevo. La parte contraria podrá someterlo a otro contrainterrogatorio. En estas dos últimas intervenciones, deberán limitarse a preguntar sobre materias nuevas que deriven del interrogatorio anterior.

21 STRONG, John W. McCormick on Evidence. $5^{\text {th }}$ Ed. Minn: Hornbook Series West Group, 1999. pp. 34 y sgtes.

22 CHIESA, Ernesto L. Tratado de Derecho Probatorio, Reglas de Evidencia de Puerto Rico y Federales. República Dominicana: Editora Corripio, 1998. p. 363. 


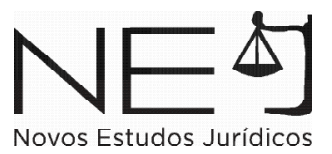

El contrainterrogatorio en materia procesal civil y mercantil tiene los mismos objetivos del penal: encontrar contradicciones o falsedades. Ahora bien, también puede ser útil para destacar las debilidades o aspectos negativos del caso de la parte contraria y también el mismo puede aportar aspectos positivos para la teoría del caso del abogado que contra interroga ${ }^{23}$.

\section{7.- LA TÉCNICA DE CONFRONTACIÓN E IMPUGNACIÓN DE TESTIGOS Y PERITOS}

La impugnación sólo puede hacerse con prueba que sea pertinente que esté relacionada a su credibilidad ${ }^{24}$. De allí la importancia de resaltar que el art. 177 del CPP permite interpretar que la prueba referente a la credibilidad de los testigos o peritos es pertinente para la solución de la controversia penal.

Por su parte el Código Procesal Civil y Mercantil, también adversativo, como derecho común o supletorio del proceso penal, dispone que a los testigos se pueden contrainterrogar con preguntas sugestivas y además dispone los motivos de impugnación de credibilidad, por lo que se pueden aplicar al proceso penal. Así manifiesta:

\section{"CREDIBILIDAD DEL TESTIGO}

Art. 356.- La credibilidad del testigo dependerá de las circunstancias o hechos que determinen la veracidad de sus declaraciones.

La parte que resulte perjudicada por la declaración de un testigo podrá alegar falta de credibilidad, mediante cualquier medio de prueba pertinente, con base en el comportamiento del testigo mientras declara o en la forma en que lo hace; en la naturaleza o carácter del testimonio, en el grado de capacidad del testigo para percibir, recordar o comunicarlos hechos sobre los que declara, en la existencia de cualquier prejuicio, interés u otro motivo de parcialidad que pudiera afectar el testimonio, o en manifestaciones o declaraciones anteriores del testigo. Si se presenta un acta o documento escrito donde conste dicha declaración, la parte que adversa tiene derecho a inspeccionar el escrito, a contrainterrogar al testigo sobre dicha declaración y a presentar prueba pertinente contra lo declarado por el testigo.

La credibilidad de un testigo podrá ser impugnada o sostenida mediante prueba de su carácter o reputación. No será admisible la prueba para impugnar o sostener la credibilidad de un testigo que 
se refiera a sus creencias religiosas, a la carencia de ellas o a sus convicciones políticas.

Pierde credibilidad un testigo cuando queda establecido en autos que su deposición está basada en un mero juicio de valor derivado de sus creencias particulares".

Las principales causas o razones para la impugnación de testigos (o peritos) en la audiencia de acuerdo con los artículos 209 del CPP y 356 del CPCM son los siguientes:

\section{COMPORTAMIENTO DE TESTIGOS O PERITOS MIENTRAS DECLARAN}

Un testigo, víctima o perito puede ser impugnado por sus actitudes, comportamiento o conducta mientras declara, cuando demuestra inseguridad, nerviosismo o cualquier otra. Esto quiere decir que el abogado puede señalar o destacar por medio de preguntas sugestivas ante el Tribunal de Sentencia (y ante el juez de paz en audiencia inicial y juez de instrucción en audiencia preliminar), el comportamiento emocional o corporal del testigo independientemente del testimonio de éste cuando exhibe irregularidades, siempre bajo el contrainterrogatorio y permitiendo al testigo o perito que explique. Por ejemplo, cuando el testigo llora o se ríe sin justificación alguna, o luce nervioso, agresivo, preocupado o inseguro cuando contesta.

\section{POR LA NATURALEZA O CARÁCTER DEL TESTIMONIO O DICTAMEN PERICIAL}

Un testigo, víctima o perito puede ser refutado en la vista o audiencia mientras está declarando por las contradicciones que realiza en su declaración previa (el interrogatorio directo u otro anterior) o por lo inverosímil que pueda parecer. Tanto las contradicciones como la improbabilidad de la existencia u ocurrencia de los hechos narrados por el testigo pueden permitirle al Juez tener dudas sobre ellos ${ }^{25}$. Si el testigo cae en contradicciones importantes, versiones increíbles o exageradas, quedaría impugnado por su propio testimonio y obviamente el abogado lograría su propósito de que no se le crea ${ }^{26}$.

\section{CAPACIDAD PARA PERCIBIR, RECORDAR O COMUNICAR LOS HECHOS}

Las personas tienen diversas capacidades sensoriales para captar la realidad. Cuando suceden hechos de violencia, las personas que están allí son por casualidad, de forma accidental, no han previsto estar presentes (a menos que sean copartícipes). Entonces, sus capacidades sensoriales, como la vista u oído, no están pendientes totalmente en un hecho delictivo. Además, el ruido, el ambiente, las distracciones, la luz, la impresión o el resultado de un delito le causa temor o una reacción de miedo, de huida o protección personal. Los testigos normalmente no están concentrados 
en lo que sucede. Por esta razón, cuando se practica en la audiencia o vista judicial el interrogatorio directo, la parte que ofrece al testigo trata de establecer su capacidad para percibir o recordar los hechos. En cambio, el abogado que contrainterroga le inquiere sobre la capacidad de visión del testigo, distancia en la que se encontraba cuando ocurrieron los hechos, puede ser relevante si fue de día o de noche por la visibilidad o grado de luz, o si fue en una época del año, la descripción del lugar en donde se encontraba y los motivos por lo que estaba allí.

De acuerdo con CHIESA APONTE "cuando un testigo declara en el juicio o vista correspondiente, lo que hace es narrar el recuerdo de sus percepciones sobre determinado asunto. Si el testigo no tiene conocimiento personal sobre el asunto no puede declarar. Pero las dificultades del testigo para percibir adecuadamente los hechos sobre los que va a declarar son pertinentes al momento de evaluar su testimonio" ${ }^{27}$. En efecto, cuando un testigo declara en audiencia, ya ha pasado suficiente tiempo para que sus recuerdos comiencen a ser olvidados o a perder detalles de los hechos.

El testigo puede ser impugnado alegando que no se encontraba con todas las capacidades sensoriales para percibir los hechos, por ejemplo, cuando vio los hechos que narra en el tribunal estaba ebrio, bajo los efectos de drogas, había muy poca visibilidad, u objetos o ruidos que obstaculizaban la visión, el oído, etc. También puede ser impugnado por su incapacidad para recordar hechos importantes o porque recurre con frecuencia al "no recuerdo". Además de las posibilidades de evaluar la capacidad de percepción del testigo, los abogados pueden intentar atacar la memoria del testigo, ya que si éste tiene mala memoria su testimonio será menos confiable. Cuando se interroga a un testigo puede ser que éste conteste que no recuerda cuando se le pregunta. En tal caso, si le conviene al abogado, puede solicitar al testigo que se refresque su memoria con algún documento que esté disponible como una declaración previa realizada en sede fiscal o de la Policía, el informe pericial, un documento público o una fotografía. El escrito o documento con el cual el testigo se refresca la memoria no tiene que haber sido preparado necesariamente por el propio testigo.

Para FONTANET, toda evidencia que demuestre al Juez que el testigo al momento de percibir los hechos ha estado bajo efectos del alcohol o drogas es admisible. Es admisible, pero está sujeto a confrontación y puede ser impugnado por su capacidad de percibir los hechos y su capacidad de recordar lo que sucedió. El que el testigo se encuentre en un grado de excitación o nerviosismo en el momento en que presenció los hechos también puede ser utilizado para impugnar la capacidad de deposición del testigo ${ }^{28}$.

$27 \quad$ CHIESA APONTE, Ernesto L. Derecho Procesal Penal de Puerto Rico y Estados Unidos. p. 325. La Regla de Evidencia número 38 de PR establece que el testigo debe declarar sobre los hechos percibidos directa y personalmente. Si esto no es así entonces se entenderá como prueba de referencia. 


\section{POR LA EXISTENCIA DE CUALQUIER PREJUICIO, INTERÉS U OTRO MOTIVO DE PARCIALIDAD POR PARTE DEL TESTIGO O PERITO}

Al desaparecer del CPP y CPCM salvadoreño, el sistema de tachas para evaluar el grado de parcialidad o imparcialidad de un testigo o perito se ha hecho necesario dotar a las partes en litigio de la posibilidad de impugnar frente al Juez la parcialidad o el interés en el resultado.

Para evaluar el grado de credibilidad de un testigo es posible hacer del conocimiento del Juez, a través de la prueba del contrainterrogatorio, las relaciones de parentesco, amistad, relaciones laborales y amorosas entre éste y el imputado o víctima. Igualmente, ayuda mucho a examinar la credibilidad de un testigo, al inquirir la existencia de relaciones de enemistad, rencor, celos profesionales o amorosos, etc.

Para hacer valer el derecho de confrontación, los jueces deben permitir, en el desarrollo del contrainterrogatorio, el escrutinio de cualquier motivo de parcialidad, tanto del testimonio que favorece como el que desfavorece a cualquiera de las partes. Ahora bien, antes de permitir la admisión de otros medios de prueba independientes para atacar la credibilidad de un testigo por parcialidad, debe consentírsele la oportunidad de aclarar o explicar dicha circunstancia en el mismo desarrollo del contrainterrogatorio ${ }^{29}$. Si la parte que contrainterroga no permite al testigo explicar el supuesto motivo de interés o parcialidad, puede hacerlo la parte que lo ofreció, en el interrogatorio redirecto (art. 348 del CPP salvadoreño). La parcialidad es una de las situaciones más eficaces para impugnar la credibilidad de un testigo. Cuando se demuestra que el testigo está parcializado puede razonablemente inferirse que no está diciendo la verdad. Por ejemplo, un copartícipe de un delito, que se convierte en colaborador eficaz o premiado por la Fiscalía, tiene un interés en obtener un criterio de oportunidad total o parcial (declarar a cambio de beneficios penales o procesales).

Muchos de los testigos son parientes, amigos o enemigos de alguna de las partes, y esta relación siempre sugiere algún grado de parcialidad ${ }^{30}$. El abogado siempre debe explorar el por qué un testigo fue presentado por la parte contraria y muchas veces es necesario hacerle la pregunta directamente sobre si conoce o tiene alguna relación con las partes. Si contesta que conoce o es amigo de la parte casi siempre se puede impugnar su testimonio por estar parcializado. Cuando el testigo niega la existencia de la relación de parcialidad o interés, entonces puede ser conveniente presentar evidencia extrínseca o independiente, como por ejemplo otro testigo que explique la existencia de la relación de prejuicio, parcialidad o interés entre el anterior testigo y la parte.

29 CHIESA APONTE, Ernesto L. Derecho Procesal Penal de Puerto Rico y Estados Unidos. p. 326. Para CHIESA, el testigo tiene derecho a explicar, admitir o negar el supuesto motivo de parcialidad de su declaración. 
Señala CHIESA APONTE que el medio "más eficaz para impugnar la credibilidad de un testigo es traer ante la consideración del juzgador declaraciones anteriores del testigo incompatibles con su testimonio en corte. Esto no solo pone en entredicho la credibilidad del testigo en relación con el asunto específico al que se refiere la contradicción, sino también la credibilidad general del testigo"31. Ordinariamente si impugna al testigo o perito de la parte contraria que ya declaró en el interrogatorio directo, mostrando a través del contrainterrogatorio, una significativa incompatibilidad entre lo dicho anteriormente con lo que está diciendo en ese momento. También procede la impugnación de la veracidad del testigo, cuando éste realiza declaraciones que había omitido anteriormente, entendiendo que esta información es básica para el descubrimiento de la verdad de los hechos controvertidos.

El art. 367 del CPCM inciso segundo es consistente con la doctrina y la regla procesal del art. 209 del CPP cuando dice: "durante el contrainterrogatorio, la parte que lo haga podrá utilizar, documentos, actas de declaraciones anteriores del testigo o deposiciones que hubiera rendido y que versen sobre los hechos en cuestión, para el efecto de demostrar o desvirtuar contradicciones, o para solicitar las aclaraciones pertinentes."

En efecto, existe una zona oscura o gris (como el lector lo califique) cuando se intenta impugnar a un testigo (o al perito) por la falta de concordancia entre una manifestación anterior, y el interrogatorio directo que se encuentra realizando ante el Juez, con relación a un documento escrito específicamente la realizada en entrevista ante Policía o Fiscalía, o cualquier otro soporte que permita comprender que hubo una declaración que es inconsistente (incluso Facebook).

En ocasiones las inconsistencias pueden ser sobre asuntos importantes, en cuyo caso podría quedar en entredicho todo lo declarado por el testigo y en otras ocasiones la impugnación es por detalles o asuntos secundarios que no afectan sustancialmente la credibilidad del testimonio. FONTANET, recomienda seguir una fórmula o un orden para maximizar la impugnación: "a) comprometer al testigo con lo declarado en el interrogatorio directo; b) establecer la importancia de la inconsistencia en el caso; c) acreditar las circunstancias en que fue prestada la primera declaración de testigo; d) dar oportunidad de que el testigo acepte o niegue la declaración anterior; y e) confrontación con declaración anterior"32. 
También los testigos pueden ser impugnados porque omitieron en declaraciones anteriores hechos importantes que se producen por primera vez cuando declaran en el proceso judicial. En tal situación se impugnaría al testigo por la omisión, ya que lógicamente debía haber expuesto con anterioridad el hecho esencial.

Si al testigo se le impugna en el tribunal por declaraciones anteriores escritas, se le debe indicar la fecha y lugar en la que persona la hizo para que lo reconozca o niegue, se le debe mostrar y entregar copia a la parte contraria.

Cuando el abogado va a usar prueba independiente, es decir evidencia extrínseca, para impugnar al testigo por haber dado una manifestación anterior es necesario que se le dé al testigo la oportunidad de que explique o niegue la misma. Prueba extrínseca puede ser lo que hubiera manifestado en un documento, correo electrónico, publicación, entrevista de prensa o cualquier otro soporte. Si no se sienta esta base en el interrogatorio del testigo, no se podría presentar la prueba extrínseca. Este requisito se cumple preguntándole al testigo que va a ser impugnado si hizo o no la declaración anterior expresándole la fecha, el lugar y quien se la hizo.

Sobre este particular en El Salvador, es pacífica la práctica en las audiencias, en los tribunales de sentencia o ante el juez de sentencia, al permitir a las partes que puedan utilizar las actas de la Policía o de la Fiscalía en la que constaran declaraciones o entrevistas de testigos o víctimas ${ }^{33}$.

Esta interpretación es correcta en tanto la prueba únicamente se puede producir en el juicio o vista pública y las actuaciones de la Policía y Fiscalía son actos de investigación, no prueba. Sin embargo, lo que interesa es que el órgano jurisdiccional tenga el mejor panorama posible para tomar una decisión justa, por lo que los tribunales de sentencia deben permitir confrontar las declaraciones de testigos con manifestaciones anteriores realizadas sea en sede fiscal o en la Policía. No se trata de convertir en prueba las actuaciones de investigación.

Esas declaraciones, por regla general, han sido vertidas con mucha mayor espontaneidad por los testigos, por haber sido obtenidas de manera pronta. "En los procesos acusatorios orales -dice QUIÑONES VARGAS- esta es la forma por excelencia utilizada por los fiscales para confrontar al testigo con las contradicciones que pudiese haber entre esa primera versión y la expresada en la vista (pública)"34; pero no solo los fiscales la utilizan, si son testigos de cargo, es seguro que un buen defensor explotará las inconsistencias.

33 El CPCM dice con respecto al contrainterrogatorio, además del art. 356, lo siguiente en el art. 367: "Durante el contrainterrogatorio, la parte que lo haga podrá utilizar, documentos, actas de declaraciones anteriores del testigo o deposiciones que hubiera rendido y que versen sobre los hechos en cuestión, para el efecto de demostrar o desvirtuar contradicciones, o para solicitar las aclaraciones pertinentes" 


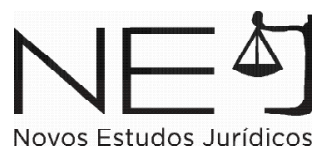

La regulación de la práctica testimonial del art. 209 del CPP y 367 del CPCM permite que un testigo que se encuentra declarando en audiencia judicial pueda utilizar un escrito para "refrescar" su memoria con relación a cualquier aspecto de su testimonio. El escrito podría ser una declaración anterior rendida por el testigo, podrían ser sus apuntes, bitácora o diarios personales con respecto a los hechos sobre los que se encuentra testificando. Como requisito de admisibilidad, exige que el escrito sea presentado en la audiencia ante el Juez y la parte contraria, para que éstos puedan examinarlo. La parte contraria puede utilizar el escrito del testigo para contrainterrogarlo, si lo considera conveniente a su estrategia probatoria.

Ahora bien, en la normativa salvadoreña se considera como medio de prueba el testimonio que se practica en audiencia (con la garantía de la inmediación del juez y sujeto a confrontación), no el contenido del escrito utilizado por el testigo para refrescar su memoria, ya que lo que se está vertiendo es el conocimiento personal y directo del testigo sobre los hechos controvertidos. Para que pueda ser admitido un documento escrito o soporte electrónico como prueba, tendría que ser considerado como prueba de referencia y, por lo tanto, es admisible, según lo dispone el art. 221 número 3 del CPP.

Si se retracta una víctima o un perito, se puede utilizar un documento previo, como una entrevista o denuncia, especialmente si está firmada, y el juez o tribunal será quien evalúe la credibilidad de lo que está declarando en estrados ante su presencia o lo hecho previamente sin su presencia.

Así dice el art. 221 del CPP, y en específico el número 3:

"Admisión excepcional del testimonio de referencia

Art. 221.- Será admisible la prueba testimonial de referencia en los casos siguientes:

1) Muerte, enfermedad grave u otra circunstancia que haga imposible o difícil que comparezca el testigo a rendir su declaración personalmente en la vista pública.

2) Operaciones policiales encubiertas.

3) Retractación de la víctima o el testigo, para controlar la credibilidad de éstas.

4) Manifestaciones expresadas de manera consciente y espontánea, en circunstancias que implicaban un perjuicio a los intereses de quien las efectúa o de un tercero en su caso".

El art. 209 del CPP salvadoreño admite que la parte que interroga a un testigo con el uso de un escrito para refrescar la memoria. Lo que pasa es que no dice nada o no se regula a qué 
le dará credibilidad el órgano jurisdiccional si a lo que está escuchando o al escrito, en caso de contradicciones. Este es un aspecto para legislar.

De conformidad al art. 209 del CPP, la declaración anterior de un testigo puede ser admitida por el Juez dándole valor probatorio al contenido mismo, en desmedro de la declaración que hubiera estado realizando en la audiencia judicial. Esta es una de las excepciones a la admisión de la prueba de referencia.

En el caso que la parte que hubiese sido afectada por la impugnación de su testigo, por medio de sus manifestaciones anteriores, puede rehabilitar la credibilidad de éste mediante prueba que demuestre que no se hizo tal declaración. Asimismo, cuando la parte afectada desarrolle su turno de interrogatorio redirecto puede hacer que su testigo impugnado tenga la oportunidad de explicar el contenido, alcance, aparente contradicción u omisión de su manifestación anterior. También la parte afectada, puede introducir como prueba para la rehabilitación de la credibilidad de su testigo otras declaraciones anteriores de éste que sean compatibles con las que está realizando en la audiencia judicial.

\section{IMPUGNANDO EL CARÁCTER O CONDUCTA EN CUANTO A VERACIDAD O} MENDACIDAD

Un testigo, una víctima o un perito pueden ser impugnados de forma general porque tiene un carácter mendaz, es decir cuando tiene fama o reputación de mentir o exagerar la verdad de los hechos. Los arts. 177 y 209 del CPP, admiten que también se impugne por el carácter o hábito a un testigo, mediante la prueba que sea idónea y pertinente. Esta regla está en consonancia con la disposición del art. 356 inciso 3ro del CPCM que dice: "La credibilidad de un testigo podrá ser impugnada o sostenida mediante prueba de su carácter o reputación. No será admisible la prueba para impugnar o sostener la credibilidad de un testigo que se refiera a sus creencias religiosas, a la carencia de ellas o a sus convicciones políticas".

Entonces, el régimen salvadoreño, bajo las reglas del CPP y CPCM citadas, la credibilidad de un testigo podrá ser impugnada o sostenida mediante prueba de su carácter o reputación. No será admisible la prueba para impugnar o sostener la credibilidad de un testigo que se refiera a sus creencias religiosas, a la carencia de ellas o a sus convicciones políticas.

Para impugnar la credibilidad de un testigo se puede ofrecer prueba sobre su reputación mendaz y para rehabilitarlo se permite ofrecer prueba de su carácter veraz. Cualquier otro tipo de evidencia, incluso sobre sus creencias religiosas o su conducta moral sería inadmisible. 


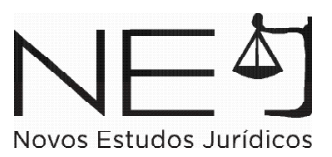

Esta impugnación se puede realizar en el contrainterrogatorio del testigo preguntando aspectos sobre la declaración que realiza o produciendo prueba independiente que demuestren la mendacidad del testigo. La impugnación del carácter se puede hacer presentando otro testigo quien declara que en su opinión el testigo de la parte contraria ha mentido o engañado al tribunal con la versión de los hechos, puesto que es su carácter o conducta y porque así es conocido. También podría permitirse evidencia de conducta específica pero la misma debe referirse directamente al asunto de la veracidad o mendacidad cuya credibilidad esté en consideración.

\section{POR CONTRADICCIÓN}

Un testigo puede ser impugnado por contradicción cuando dice algo que es falso, inexacto o erróneo. Al impugnarse por contradicción se podría contrainterrogar con las respuestas que brindó en el interrogatorio directo o se puede presentar cualquier evidencia extrínseca, como por ejemplo evidencia documental o la declaración de otro testigo que desmienta lo declarado por el testigo que va a ser impugnado. Para lograr el propósito de establecer la contradicción se podría utilizar cualquier prueba, incluyendo declaraciones judiciales efectuadas en otros casos que tengan una conexión o relación por el cual está declarando.

En el desarrollo del contrainterrogatorio de un testigo, el abogado que se encuentra llevando a cabo esta técnica puede intentar demostrar al Juez o al jurado la existencia de contradicciones en el testimonio. Esto quiere decir, que se admite en el contrainterrogatorio demostrar que el testigo se contradice en su propio testimonio o, en su caso, con la declaración testimonial que se encuentra vertiendo en audiencia con anteriores manifestaciones testificales sobre el mismo asunto en controversia.

\section{7.- INTERROGATORIO REDIRECTO Y RECONTRAINTERROGATORIO}

El art. 209 del CPP manifiesta que luego que el abogado de la parte contraria termina el contrainterrogatorio, el abogado (o fiscal) que llevó a cabo el directo del testigo tiene la opción de hacer el interrogatorio redirecto. Dice el art. 209 CPP “La parte que lo sometió al primer interrogatorio, podrá interrogarlo nuevamente, después del contrainterrogatorio; así como también, la parte contraria podrá someterlo a nuevo contrainterrogatorio, a continuación del precedente. Estas dos últimas intervenciones deberán limitarse a preguntar sobre materias nuevas procedentes del interrogatorio inmediato anterior". 
Esto último no quiere decir, que en algún momento para que sea efectivo el contrainterrogatorio se tenga que abrir a hechos relevantes y pertinentes para rehabilitar al testigo. El juez puede requerir a la parte que realice el interrogatorio a mantenerse en los hechos, si considera que está abusando, siempre a impulso de parte por medio de las objeciones.

\section{8.- EL CONTROL DE LA AUDIENCIA POR MEDIO DE LA FORMULACIÓN DE LAS OBJECIONES}

No se puede articular un modelo de juicio oral o por audiencias si no se establecen mecanismos o recursos que permitan a las partes solicitar al juez un control sobre la prueba, la conducta de las fuentes de prueba o de los sujetos procesales, de forma rápida y eficiente.

Un juez en el sistema adversativo, en principio, tiene limitada su intervención en los interrogatorios, puede controlar la conducta de los abogados muy excepcionalmente para efectos de mantener el orden, pero oficiosamente no puede intervenir en la práctica de prueba, requiere el impulso de los litigantes. Si los litigantes no objetan, no pueden hacerlo el juez, por ser un tercero imparcial, y porque la objeción es una facultad de las partes.

La objeción, como recurso o medio impugnativo, no tienen una raíz en el derecho procesal continental. Las objeciones son de origen anglosajón, aunque el derecho procesal salvadoreño las incorporó por medio de la redacción de las más usuales, aunque se entiende que no es una lista cerrada o taxativa, sino ejemplificativa.

Si bien, el art. 209 del CPP regula limitadamente el concepto y alcance de la objeción, ya que solo dice: "objetar las preguntas que se formulen por las otras partes". El legislador olvidó que las objeciones no se limitan solo a los interrogatorios de testigos, sino que también pueden ser útiles y son permitidas en el interrogatorio de peritos. Es necesario, entonces, hacer un esfuerzo hermenéutico con el CPP y el CPCM para aplicarlas correctamente al proceso penal.

El CPP expresa en el art. 210 "Objeciones. Procedencia. Art. 210.- Las partes podrán interponer objeciones a las preguntas formuladas por la parte contraria, durante los interrogatorios a testigos o peritos. Las objeciones deben ser oportunas y específicas.

Si no se objeta oportunamente en la audiencia, se entenderá que se ha renunciado a ejercer este derecho. Las partes podrán objetar el comportamiento, conducta o lenguaje no verbalizado.

Las preguntas formuladas al testigo en el interrogatorio directo y el contrainterrogatorio podrán ser objetadas de manera continua. 


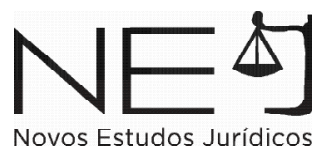

Las respuestas de los testigos deberán ser directas, concretas y pertinentes a las preguntas que se les formulen y sobre los aspectos que tenga conocimiento personal, las que podrán ser objetadas por las partes. En sus declaraciones los testigos no podrán emitir especulaciones".

El procedimiento en el CPP para que el juez decida sobre la procedencia o fundamentación de la objeción es el siguiente: "Trámite de la objeción Art. 211.- Interpuesta la objeción, el juez o tribunal resolverá inmediatamente, admitiéndola o rechazándola; si la admite, el juez en su caso indicará al interrogador que reformule su pregunta. Lo resuelto por el juez admitirá el recurso de revocatoria."

La objeción, esencialmente trata de evitar la producción de prueba que sea inadmisible por ser impertinente, inútil, inconducente, repetitiva, superflua o ilegal, entre otras razones justificables. Incluso las partes pueden defenderse de la conducta del abogado contrario o del juez de lo penal.

La parte que efectúa una objeción pretende llamar la atención del juez o tribunal de lo penal ante la actividad de la parte contraria. Es decir, pretende advertir al juez de lo penal que no se debe permitir la conducta y actividad probatoria de la parte contraria y que se debe evitar incurrir en errores, especialmente de permitir la producción de prueba impertinente. Además, la objeción puede justificarse, en sentido amplio, como la expresión de una insatisfacción de una de las partes ante la conducta del testigo o perito, del procurador de la parte contraria o del mismo juzgador en la audiencia probatoria, como las dilaciones indebidas, la mala fe o deslealtad procesal del litigante.

Bajo esas reglas las partes podrán objetar el intento del litigante de la parte contraria de introducir prueba que es contraria a las disposiciones del CPP. Como requisito de admisibilidad de una objeción se requiere que sea oportuna, fundada y específica. Como se ha dicho previamente el Código Procesal Civil y Mercantil (CPCM) es utilizado como derecho supletorio en el proceso penal. Así que dice el art. 407 del CPCM, en su carácter de derecho común supletorio: "Objeciones. Procedencia Art. 407.- Las partes podrán objetar la prueba que se pretenda introducir en las audiencias con violación a lo establecido en este código. Las objeciones que se interpongan tienen que ser oportunas y específicas. La parte que formule una objeción deberá fundamentarla. Si no se objeta oportunamente en audiencia, se entenderá que se ha renunciado a ejercer este derecho.

El juez o tribunal fundamentará la admisión o el rechazo de la objeción interpuesta. Las partes podrán interponer recurso de revocatoria a la decisión del juez o tribunal".

La objeción, por ser un medio de impugnación de parte, únicamente la puede efectuar el litigante no el juez de lo penal. Es decir, requiere impulso de parte. Pero la parte que no objeta oportunamente entenderá que ha renunciado a su derecho. 
Las objeciones tienen también, una finalidad estratégica, por lo que su uso dependerá de la misma preparación técnica del abogado. Si la actividad de la contraparte no le ha causado daño, el procurador deberá valorar si vale la pena objetar. Obviamente, si considera que le hace daño deberá objetar, especialmente si la pregunta o respuesta es impertinente o si es sugestiva (cuando está prohibida en el interrogatorio directo como el redirecto).

El juez de lo penal tendrá la libertad de decidir la admisión o rechazo de la objeción, fundando su decisión de manera verbal. La parte que no esté de acuerdo podrá pedir que se revise verbalmente la decisión del juez de lo penal. La objeción realizada de manera oportuna ante una prueba no admitida puede fortalecerla decisión del tribunal superior que revise una sentencia de primera instancia.

A manera de ejemplo o de ilustración, y conforme al CPCM, pueden ser objetables durante las audiencias:

Las preguntas formuladas por los procuradores durante los interrogatorios. Es decir, las preguntas efectuadas por los litigantes pueden ser objetables si son impertinentes, sugestivas, repetitivas, capciosas, compuestas, especulativas, ambiguas o cuando se asumen hechos no establecidos (art. 408 del CPCM);

Las respuestas de los peritos, testigos y partes si las respuestas son prueba de referencia, o si el testigo emite opinión o si contesta más allá de lo preguntado (art. 409 del CPCM); y,

La conducta de los abogados, por ejemplo, si durante el interrogatorio cita de manera incorrecta lo expresado por un testigo; si tiene una conducta irrespetuosa hacia el testigo, parte o perito; o si obstaculiza las respuestas del testigo o lo intimida (art. 410 del CPCM).

El que un litigante se refiera a una prueba en las alegaciones finales sin haberla practicado es objetable por la parte contraria. Ello es así, porque el juez de lo penal deberá juzgar sobre la prueba que ha desfilado en la audiencia y no sobre supuestos o meras alegaciones. Ni por las afirmaciones de los procuradores.

El sistema de objeciones arriba descrito no es una enumeración exegética, sino que tiene un papel ilustrativo, para el proceso penal, tomando en consideración las reglas supletorias tanto del proceso penal de adultos como el proceso civil en su carácter supletorio o como derecho procesal común, ver los arts. 210 y 211 del CPP y arts. 407 a 410 y 413 del CPCM. 


\section{CONCLUSIÓN}

El derecho procesal penal salvadoreño adoptó desde 1996, el modelo adversativo con algunas de las reglas de evidencia de Puerto Rico, como es el interrogatorio a testigos y peritos. Fue el resultado del intercambio cultural entre operadores jurídicos salvadoreños y puertorriqueños. El cambio no fue fácil, pues la cultura jurídica del modelo procesal iberoamericano sigue siendo relevante.

EI CPP establece las reglas para descubrir la verdad en materia criminal. Se admite que en las audiencias la parte contraria, luego del interrogatorio directo, pueda impugnar al órgano de prueba o a su testimonio. Si resiste la fuente de prueba, entonces, habrá mayor probabilidad que su dicho sea verdad.

Ahora se puede afirmar que las reglas de interrogatorio y contrainterrogatorio son parte de las disposiciones probatorias y forenses en El Salvador, incluso para justicia penal juvenil, familia, civil y mercantil, contencioso administrativo; y, el procedimiento administrativo sancionador. No se podría concebir en la actualidad, en el derecho procesal salvadoreño, una actividad probatoria sin el uso de las técnicas descritas anteriormente. En efecto, se ha descubierto lo útil que puede ser un contrainterrogatorio sugestivo para descubrir testigos que mienten, o que no pueden ser confiables para el tribunal. $\mathrm{O}$ en su caso, se puede descubrir peritos cuyas conclusiones o el procedimiento técnico científico utilizado no es confiable.

El proceso de implementación de la reforma procesal penal no está terminado. La realidad indica que se requiere revisar tanto la práctica como las reglas para adecuarlas a una investigación diligente, a la búsqueda de prueba y a su práctica en un modelo adversativo. Equilibrando la protección y acceso a la justicia de la víctima y las reglas del debido proceso, respetando la presunción de inocencia, defensa y confrontación, así como el derecho de audiencia.

En estas circunstancias de la pandemia por covid-19 y los riesgos asociados a su propagación, han impactado en las garantías del debido proceso. Se han reducido las audiencias presenciales, y se pretende celebrarlas virtualmente. Esto disminuye la posibilidad de confrontar debidamente a la prueba de cargo. Además de las dificultades de comunicación espontánea que pueden tener los defensores con los imputados. 


\section{REFERENCIA}

CASTILLO BARRANTES, J. Enrique. Ensayos sobre la Nueva Legislación Procesal Penal. San José: Colegio de Abogados, 1977.

CHIESA APONTE, Ernesto L. Derecho Procesal Penal de Puerto Rico y Estados Unidos. San Juan: Editorial Forum, 1995. CHIESA, Ernesto L. Tratado de Derecho Probatorio, Reglas de Evidencia de Puerto Rico y Federales. República Dominicana: Editora Corripio, 1998.

GIMENO SENDRA, José Vicente. Fundamentos del Derecho Procesal, jurisdicción, acción y proceso. Editorial Civitas S.A., 1981.

GIMENO SENDRA, José Vicente; Derecho Procesal. Proceso Penal. Valencia: Tirant lo Blanch, 1993.

GIMENO SENDRA, Vicente. Derecho Procesal Penal. Madrid: Editorial COLEX, 2004.

GIMENO SENDRA, José Vicente, Derecho Procesal Civil. Madrid: Editorial COLEX, 2004.

GOLDBERG, Steven H. Mi primer Juicio Oral. Buenos Aires: Heliasta, 1994.

FAIRÉN GUILLÉN, Víctor. Doctrina General del Derecho Procesal. Hacia una teoría y Ley procesal generales. Barcelona: Librería Bosch, 1990.

FONTANET, Julio. Principios y Técnicas de la Práctica Forense. 2ª . Ed., San Juan Puerto Rico: Jurídica Editores, 2002.

GONZALEZ-CUELLAR SERRANO, Nicolás. Proporcionalidad y Derechos Fundamentales en el Proceso Penal, Madrid: Editorial Colex, 1990.

HIDALGO MURILLO, José Daniel. Introducción al Nuevo Código Procesal Penal. San José: Investigaciones Jurídicas S.A., 1998.

IMWINKELRIED, Edward J. Evidentiary Foundations, 5 Ed., USA: LexisNexis, 2002.

MIRANDA ESTRAMPES, Manuel. La Mínima Actividad Probatoria en el Proceso Penal. Barcelona: José María Bosch Editor, 1997.

MORENO CATENA, Víctor, El Secreto en la Prueba de Testigos del Proceso Penal. Madrid: Editorial Motecorvo S.A, 1980.

MURRAY, Peter L. Basic Trial Advocacy. USA: Aspen Law \& Business, 1995.

QUIÑONES VARGAS, Héctor. Las Técnicas de Litigación Oral en el Proceso Penal Salvadoreño. El Salvador: PAS/DPK Consulting, 2003.

SANDOVAL ROSALES, Rommell Ismael y AAVV. Código Procesal Penal comentado: volumen 1. San Salvador: Consejo Nacional de la Judicatura, 2018.

SANDOVAL ROSALES, Rommell Ismael. Las Técnicas y Destrezas del Interrogatorio Oral en el Proceso Penal de la República de Panamá. 2013. Revista acceso: http://www.accesocapacitacion.com

SANDOVAL ROSALES, Rommell Ismael. Las técnicas de litigación en el Código Procesal Civil y Mercantil. Revista DeLegibus. N. 4, UCA, 2010.

SANDOVAL ROSALES, Rommell Ismael. La prueba de testigos en el Nuevo Código Procesal Civil y Mercantil. UCA Editores, 2009.

STRONG, John W. McCormick on Evidence. $5^{\text {th }}$ Ed. Minn: Hornbook Series West Group, 1999. 